\title{
Drug adherence to olmesartan/amlodipine fixed combination in an Italian clinical practice setting
}

This article was published in the following Dove Press journal:

ClinicoEconomics and Outcomes Research

22 April 2014

Number of times this article has been viewed

\section{Luca Degli Esposti \\ Stefania Saragoni \\ Stefano Buda \\ Ezio Degli Esposti}

Clicon Srl Health, Economics and Outcomes Research, Ravenna, Italy

Correspondence: Luca Degli Esposti

Clicon Srl, Via Salara, 36, 48I2I

Ravenna, Italy

Tel +39054 438393

Fax +39054 42I 2699

Email luca.degliesposti@clicon.it
Objective: To investigate the criteria for prescribing a combination pill for hypertensive patients, and whether the combination pill improves medication adherence.

Materials and methods: This was a retrospective cohort study, performed in three Italian local health units. We selected all adult subjects who received at least one prescription of antihypertensive drugs between September 1, 2011 and December 31, 2011 (the enrollment period). The date of the first antihypertensive claim was defined as the index date. For each patient, we documented the antihypertensive drug treatments and evaluated patients' adherence to treatment, which was calculated, separately, as the proportion of days covered in the two 6-month periods preceding and following the index date. Only patients treated with olmesartan and/or amlodipine as a single therapy, or as a two-pill combination in the period prior the index date were included. Changes in adherence levels were compared in subjects who moved to the fixed combination of olmesartan/amlodipine after the index date and in subjects who did not.

Results: A cohort of 21,008 subjects with a 6-month history of a prescription of olmesartan and amlodipine as two pills in a combination treatment, or as single-pill treatment, was obtained. Subjects treated with the two-pill combination treatment moved to the olmesartan/amlodipine fixed combination treatment more frequently than did subjects with a single-pill treatment $(P<0.001)$. Comparing the postindex date period to the preindex date period, adherence to treatment was found to be higher in the 239 subjects who moved to the olmesartan/amlodipine fixed combination therapy (from $59.0 \%$ to $78.7 \% ; P<0.001$ ), than in the 20,769 subjects who did not move to the olmesartan/amlodipine fixed combination therapy (from $56.3 \%$ to $63.0 \%$, $P<0.001)$.

Conclusion: The results of the present study show that the fixed combination of olmesartan/ amlodipine contributes to increasing treatment adherence in subjects previously treated with a two-pill combination therapy or a single-pill therapy.

Keywords: pharmaceutical database, blood pressure, hypertension, antihypertensive therapy, multi-drug pill, proportion of days covered

\section{Introduction}

Hypertension is a highly prevalent condition and an important risk factor for cardiovascular (CV) morbidity and mortality. ${ }^{1,2}$ Hypertension affects nearly one out of four adults in Italy, with a prevalence of about $60 \%$ in a population $\geq 65$ years old. ${ }^{3}$ Disappointingly, only two-thirds of treated hypertensive patients had controlled blood pressure (BP), ${ }^{4}$ and most of them required more than one antihypertensive agent to achieve and maintain recommended BP goals. ${ }^{5-7}$ This lack of medical success and the need for multidrug therapy are some of the reasons why new antihypertensive drugs continue to be developed, and it also explains the interest in 
fixed-combination antihypertensive agents. The European Society of Hypertension-European Society of Cardiology guidelines recommend combination therapy as a first-line treatment option for hypertension that will likely not be controlled on monotherapy (systolic BP $>20 \mathrm{mmHg}$ or diastolic BP $>10 \mathrm{mmHg}$ above target BP) because of evidence showing that only a minority of patients will achieve and maintain BP goals on monotherapy. ${ }^{7}$ Increasingly, a single-pill combination containing two antihypertensive drugs with complementary mechanisms of action offers potential advantages, including simplification of treatment regimens, more convenient drug administration, increased compliance, and reduced health care costs. ${ }^{6,8,9}$ Several fixedcombination therapies consisting of two antihypertensive agents are available. ${ }^{9}$ Preferred drug classes for combination regimens include angiotensin-converting enzyme inhibitors, angiotensin II receptor blockers, calcium channel blockers, and diuretics, with selection dependent on individual patient factors, including additional $\mathrm{CV}$ risk factors and comorbidities. ${ }^{5,7}$ Recently, a single-pill combination of olmesartan medoxomil/amlodipine has become available for clinical practice use in Italy. Hence, in the present study, we attempted to investigate the criteria for prescribing the combination pill for hypertensive patients in the context of clinical practice, and to determine whether the combination pill improves medication adherence. The study was conducted using data from the pharmaceutical services database.

\section{Materials and methods Data source}

The study was based on administrative databases maintained by three local health units (LHU) located in three Italian regions: Lombardy; Emilia-Romagna; and Campania. The LHU Ethics Committees approved of the study. In the Medications Prescription Database, the LHU routinely measures the volume of expenditure generated by the dispensing of drugs to the enrollees. The data available in each prescription claim include the patient's national health number, the prescribing physician's number, the anatomicaltherapeutic-chemical (ATC) code of the drug delivered, the number of packs, the number of units per pack, the dosage, the unit cost per pack, and the prescription date. Using the numeric code released to each citizen by the LHU as a unique identifier, this database was linked with the Beneficiaries' Database, which listed some patients' demographic characteristics such as their date of birth, sex, place of residence, physician's license number, and the start and end registration dates. Moreover, the Hospital Discharge Database was also included, which provided hospitalization data, such as the discharge diagnosis codes that were classified according to the International Classification of Diseases, Ninth Revision, Classification Modified (ICD-9-CM). Finally, the Mortality Database was also used, where patients' death data were recorded. It was not possible to retrieve the cause of death from death certificates. Universal health care coverage in Italy allows for the completeness and comprehensiveness of information contained in these databases, which have been used in previous epidemiological studies. ${ }^{10,11}$ The Italian Ministry of Health (Rome, Italy) reported that archives are $100 \%$ complete and $95 \%$ accurate. ${ }^{12}$ In order to guarantee patient privacy, each subject was assigned an anonymous and unique alphanumeric code.

\section{Cohort definition}

This was a retrospective cohort study, which selected subjects aged 18 years and older, who received at least one prescription of antihypertensive drugs (diuretics [ATC code C03]; betablockers [ATC code C07]; calcium channel blockers [ATC code C08]; angiotensin-converting enzyme inhibitors [ATC code $\mathrm{C} 09 \mathrm{~A} / \mathrm{B}$ ]; angiotensin-receptor blockers [ATC code $\mathrm{C} 09 \mathrm{C} / \mathrm{D}$ ]; and/or other antihypertensive drugs [ATC code C02] between September 1, 2011 and December 31, 2011 [enrollment period]). The date of the first antihypertensive claim was defined as the index date. We excluded records of subjects who died or moved to other LHU during the study period. For each subject, we compared the antihypertensive drug treatments (ADTs), as well as the patient's adherence to treatment in the 6 months preceding and following the index date. For analysis purposes, we included only subjects who, in the previous 6-month period, received at least a prescription of olmesartan (ATC code C09CA08, C09DA08) and/or amlodipine (ATC code $\mathrm{C} 08 \mathrm{CA} 01$ ) as a single therapy or in a two-pill combination. In order to define the patients' clinical characteristics, in the 12 months before the index date, we evaluated prescriptions of hypoglycemic drugs (ATC code A10; at least two prescriptions) and hospital admissions for hypertension (ICD-9-CM code 401-405), myocardial infarction or other ischemic heart disease (ICD-9-CM code 410-414), heart failure (ICD-9-CM code 428), cerebrovascular disorders (ICD-9-CM code 430-438), or vascular diseases (ICD-9-CM code 440-442). ${ }^{13}$

\section{Adherence to ADT}

The adherence to ADT was determined separately in the two 6-month study periods, grouping the enrolled subjects as follows: subjects treated with olmesartan or amlodipine in a single-pill treatment; or subjects treated with a free-drug 
combination in the preceding period, who either moved or did not move to a fixed combination of olmesartan/amlodipine in the following period. Adherence to ADT was estimated as the percentage of days a subject had tablets available (proportion of days covered [PDC]), from the first delivery of ADT until the last day of the 6-month follow-up period, regardless of any gap in therapy. Based on the method of Catalan and LeLorier, ${ }^{14}$ the 6-month intervals were separated into treatment episodes of continuous ADT use. The PDC corresponded to the total of number of days' supply of medication dispensed within each episode, divided by the 6-month follow-up period, and multiplied by 100 . The period covered by a prescription was calculated by the number of tablets in the dispensed packs of drugs. We assumed a treatment schedule of one tablet per day regarding prescriptions of agents from the same drug class, considering a possible stockpiling of medication for future use, while we assumed one tablet per agent per day regarding prescriptions containing agents from antihypertensive different classes, identifying these as a combined therapy. The method we used avoided double counting in the case of overlapping refills. Any remaining tablets at the end of the study period were not accounted for. Consistent with data in the literature, subjects with a PDC $>80 \%$ were defined as adherent to ADT. ${ }^{15}$

\section{Statistical analysis}

Data were summarized as the mean \pm standard deviationfor continuous variables, and as numbers (percentages) of subjects for categorical variables. Pearson's chi-square and one-way analysis of variance tests were used to evaluate differences in baseline characteristics across the cohort of patients. McNemar's test was used to assess the change in the proportion of adherent patients from the pre- to the postindex date period. Two-tailed $P$-values $<0.05$ were considered statistically significant. All statistical analyses were conducted using Stata software, version 12.1 (StataCorp LP, College Station, TX, USA).

\section{Results}

Out of a population of about 2,140,000 beneficiaries, 432,253 subjects had at least a prescription of antihypertensive drugs filled from September 1, 2011 to December 31, 2011. Of these, 2,395 were previously treated with olmesartan and amlodipine as a two-pill combination treatment and 18,613 were previously treated with olmesartan or amlodipine as a single-pill treatment (Figure 1). Subjects treated with the two-pill combination treatment were significantly $(P<0.001)$ more frequently diabetic and had significantly $(P<0.001)$ more previous $\mathrm{CV}$ events than subjects treated with the single-pill treatment (Table 1). Subjects treated with the two-pill combination treatment moved to olmesartan/amlodipine fixed combination treatment more frequently than did subjects treated with a single-pill treatment $(P<0.001)$ (Figure 1), who were independent from the presence of diabetes and/or previous CV events (Table 1). Of the 21,008 enrolled patients (Table 2), 239 (1.1\%) moved to olmesartan/

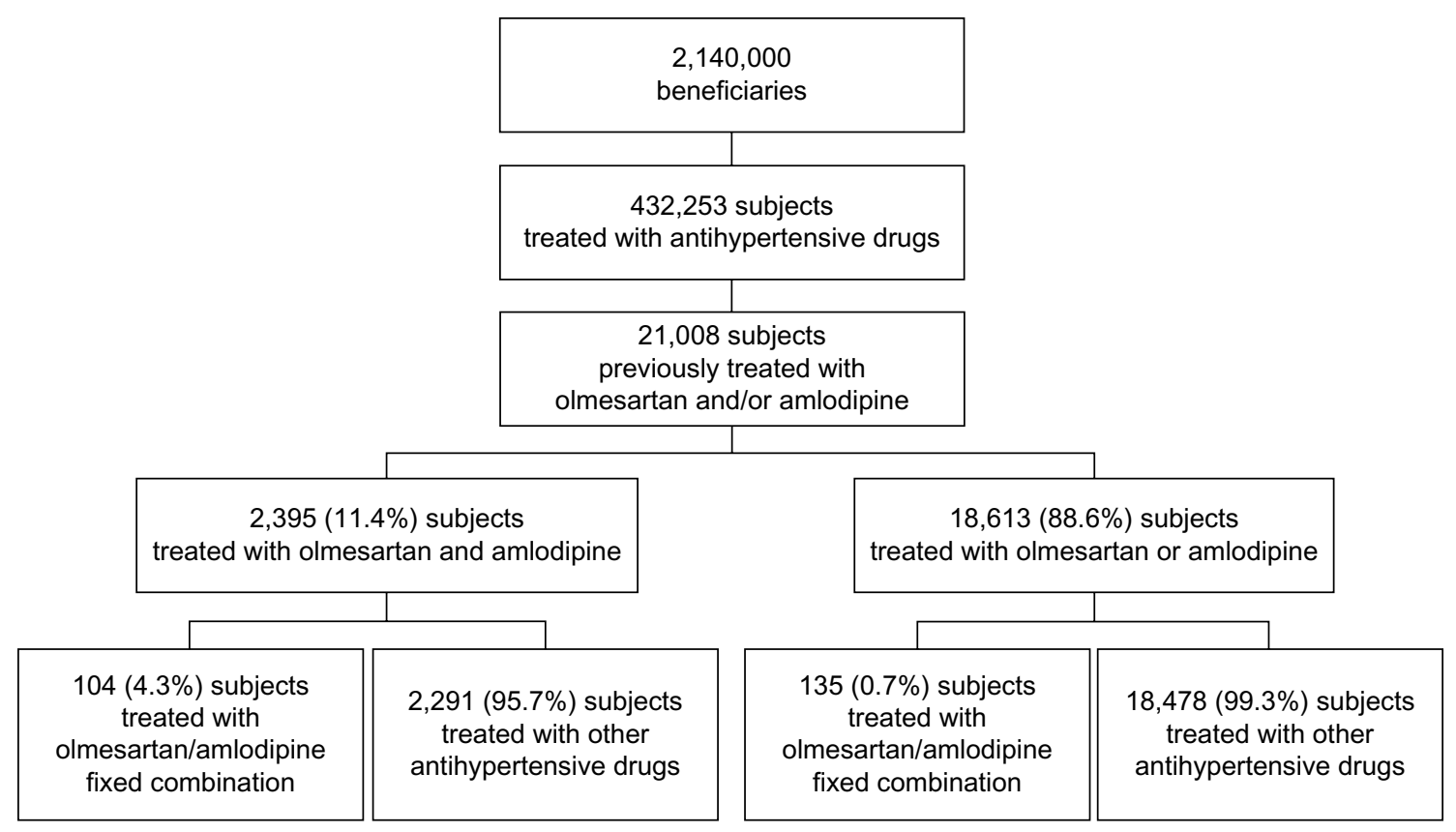

Figure I Subjects evaluated according to the prescribed antihypertensive treatment. 
Table I Characteristics of the enrolled subjects according to the pretreatment index

\begin{tabular}{|c|c|c|c|}
\hline \multirow[t]{2}{*}{ Characteristic } & \multicolumn{2}{|l|}{ Subjects enrolled $(\mathrm{N}=\mathbf{2} \mathrm{I}, \mathbf{0 0 8})$} & \multirow[t]{2}{*}{ P-values } \\
\hline & $\begin{array}{l}\text { Previously treated with } \\
\text { olmesartan and amlodipine }\end{array}$ & $\begin{array}{l}\text { Previously treated with } \\
\text { olmesartan or amlodipine }\end{array}$ & \\
\hline Subjects, n (\%) & $2,395(11.4)$ & $18,613(88.6)$ & \\
\hline Age (years) mean $\pm S D$ & $67.9 \pm 11.9$ & $64.4 \pm 12.7$ & $<0.001$ \\
\hline Male sex $\%$ & 53.4 & 50.0 & 0.002 \\
\hline Diabetes \% & 24.5 & 10.8 & $<0.001$ \\
\hline Previous cardiovascular events \% & 10.6 & 3.0 & $<0.001$ \\
\hline
\end{tabular}

Abbreviations: $\mathrm{N}$, total number of subjects; $\mathrm{n}$, sample number; $\mathrm{SD}$, standard deviation.

amlodipine fixed combination therapy during the postindex date period, while 20,769 (98.9\%) were mainly treated with olmesartan and amlodipine as a two-pill combination treatment $(9.6 \%)$ or olmesartan or amlodipine as a single-pill treatment also combined with other antihypertensive drugs (87.9\%) (Table 3). As shown in Table 2, the 239 patients who moved to olmesartan/amlodipine fixed combination therapy were more likely to have diabetes and a previous two-pill combination treatment. Among these patients, we compared the postindex date period to the preindex date period, and we observed an increase in the percentage of patients adherent to the treatment, both in the 104 subjects coming from the two-pill combination treatment, and in the 135 subjects coming from the single-pill treatment (from 61.5\% [pre-index adherence level] to $76.0 \%$ [post-index adherence level], $+24 \%$ increase; and from $57.0 \%$ to $80.7 \%,+42 \%$, respectively) (Figure 2). Also, among the 20,769 subjects who did not move to the olmesartan/amlodipine fixed combination therapy, when we compared the postindex date period to the preindex date period, we observed an increase in the percentage of patients who were adherent to the treatment both in the 2,291 subjects coming from the two-pill combination treatment, and in the 18,478 subjects coming from the single-pill treatment (from $66.7 \%$ to $70.8 \%,+6 \%$; and from $55.0 \%$ to $62.0 \%,+13 \%$, respectively) (Figure 3). The percentage of adherent patients observed in the postindex period among the 239 subjects who moved to olmesartan/amlodipine fixed combination therapy compared with that observed among the 20,769 subjects who did not move to olmesartan/amlodipine fixed combination therapy resulted in significant differences (from $59.0 \%$ to $78.7 \%,+33 \%, P<0.001$; and from $56.3 \%$ to $63.0 \%,+12 \%$, $P<0.001$, respectively); the evaluated increase in treatment adherence in patients who moved to the olmesartan/amlodipine fixed combination therapy resulted in significantly higher differences than did the increase in treatment adherence among the patients treated with the other antihypertensive drugs $(P<0.001)$.

\section{Discussion}

Hypertension represents a significant economic burden, absorbing a large and growing share of health care resources. The economic burden of uncontrolled hypertension is primarily clinical, related to CV morbidity, including coronary heart and cerebrovascular diseases, and consequently economic due to the costs of managing cardiovascular events as well as the cost of medications and physician visits. ${ }^{16}$ The high prevalence of hypertension in the real-world clinical setting is partly due to a lack of awareness of BP levels, but also to

Table 2 Characteristics of the subjects who moved to olmesartan/amlodipine fixed combination therapy, and those who did not move to olmesartan/amlodipine fixed combination therapy

\begin{tabular}{|c|c|c|c|}
\hline \multirow[t]{2}{*}{ Characteristic } & \multicolumn{2}{|l|}{ Subjects enrolled $(\mathbf{N}=\mathbf{2} \mathrm{I}, \mathbf{0 0 8})$} & \multirow[t]{2}{*}{$P$-values } \\
\hline & $\begin{array}{l}\text { Moved to fixed combination } \\
\text { olmesartan/amlodipine }\end{array}$ & $\begin{array}{l}\text { Treated with other } \\
\text { antihypertensive drugs }\end{array}$ & \\
\hline Subjects n (\%) & $239(1.1)$ & $20,769(98.9)$ & \\
\hline Age (years) mean \pm SD & $64.4 \pm 11.6$ & $64.8 \pm 12.6$ & 0.661 \\
\hline Male sex $\%$ & 49.4 & 50.4 & 0.750 \\
\hline Diabetes \% & 16.6 & 12.3 & 0.013 \\
\hline Previous cardiovascular events \% & 5.9 & 3.9 & 0.117 \\
\hline Previous antihypertensive treatment, $\mathrm{n}(\%)$ & & & 0.001 \\
\hline Olmesartan and amlodipine & $104(43.5)$ & 2,291 (11.0) & \\
\hline Olmesartan or amlodipine & $135(56.5)$ & I8,478 (89.0) & \\
\hline
\end{tabular}

Abbreviations: $N$, total number of subjects; $n$, sample number; SD, standard deviation. 
Table 3 Postindex treatment of subjects who did not move to olmesartan/amlodipine fixed combination therapy

\begin{tabular}{llc}
\hline Type of treatment & \multicolumn{2}{l}{$\begin{array}{l}\text { Treated with other } \\
\text { antihypertensive drugs }\end{array}$} \\
\cline { 2 - 3 } & $\mathbf{n}$ & $\%$ \\
\hline $\mathrm{N}$ & 20,769 & \\
Olmesartan and amlodipine & 1,997 & 9.6 \\
Olmesartan or amlodipine & 15,735 & 75.8 \\
Olmesartan or amlodipine, with & 2,521 & 12.1 \\
other antihypertensive drugs* & & \\
Other CCBs/All antagonists & 211 & 1.0 \\
Other antihypertensive drugs & 305 & 1.5 \\
\hline
\end{tabular}

Note: *Other antihypertensive drugs include diuretics, beta blocking agents, and ACE inhibitors.

Abbreviations: $\mathrm{N}$, total number of subjects; $n$, sample number; $\mathrm{CCBs}$, calcium channel blockers; All, angiotensin II; ACE, angiotensin-converting enzyme.

patients not achieving recommended treatment targets. Failure to achieve target BP levels may be related to physicians' prescribing habits, and/or patients' adherence and persistence to their antihypertensive medications. ${ }^{16}$ Treatment adherence is an important issue for a chronic disease such as hypertension, with improvements in adherence expected to result in better long-term clinical outcomes, including reduced $\mathrm{CV}$ and renal morbidity/mortality and, consequently, containment of health care costs. ${ }^{17}$ In fact, some studies have shown a direct correlation between noncompliance to antihypertensive therapy and increased health care expenditures. ${ }^{17,18}$ Treatment adherence to antihypertensive drugs has been previously estimated using administrative databases from drug reimbursement programs. ${ }^{19-22}$ A positive benefit of these studies is that they offer the opportunity to carry out clinical audits and evaluative research, they inform the planning and management of services, and they provide clinicians with accurate estimates of the outcomes of care. ${ }^{23}$ They represent a complementary approach, rather an alternative to clinical trials, and can contribute to evaluate health care in everyday practice and how to improve the organization of services and individual pharmacological treatment. ${ }^{24}$

In the present study, we have determined the adherence to antihypertensive agents. While treatment persistence reflects the duration over which a patient had not discontinued their drug therapy, treatment adherence refers to the intensity of drug use during the follow-up period. ${ }^{25}$ Currently, the two most commonly used measures of medication adherence based on pharmacy data are the medication possession ratio and the PDC methods. The main difference between these two measures is that the maximum PDC is 1.0 (or $100 \%$, if expressed as percentage), which indicates full adherence, whereas the medication possession ratio accounts for overprescription and can have a value $>1.0 .{ }^{25}$ We calculated adherence in terms of the percentage of days covered. This percentage was arbitrarily selected, but it was based on the assumption that patients who took at least $80 \%$ of their prescribed medications would benefit. ${ }^{14}$ This dichotomous cutoff value was found to be reasonable for $\mathrm{CV}$ medications, even in the presence of cases of overprescription of the drug. ${ }^{25}$ Hence, we believe our definition is relevant to clinical practice goals for treatment. Evidence from meta-analyses has shown that the use of an antihypertensive, single-pill combination therapies, when compared with corresponding free-drug combinations, is associated with significantly greater rates of treatment adherence to medications, as well as with potential

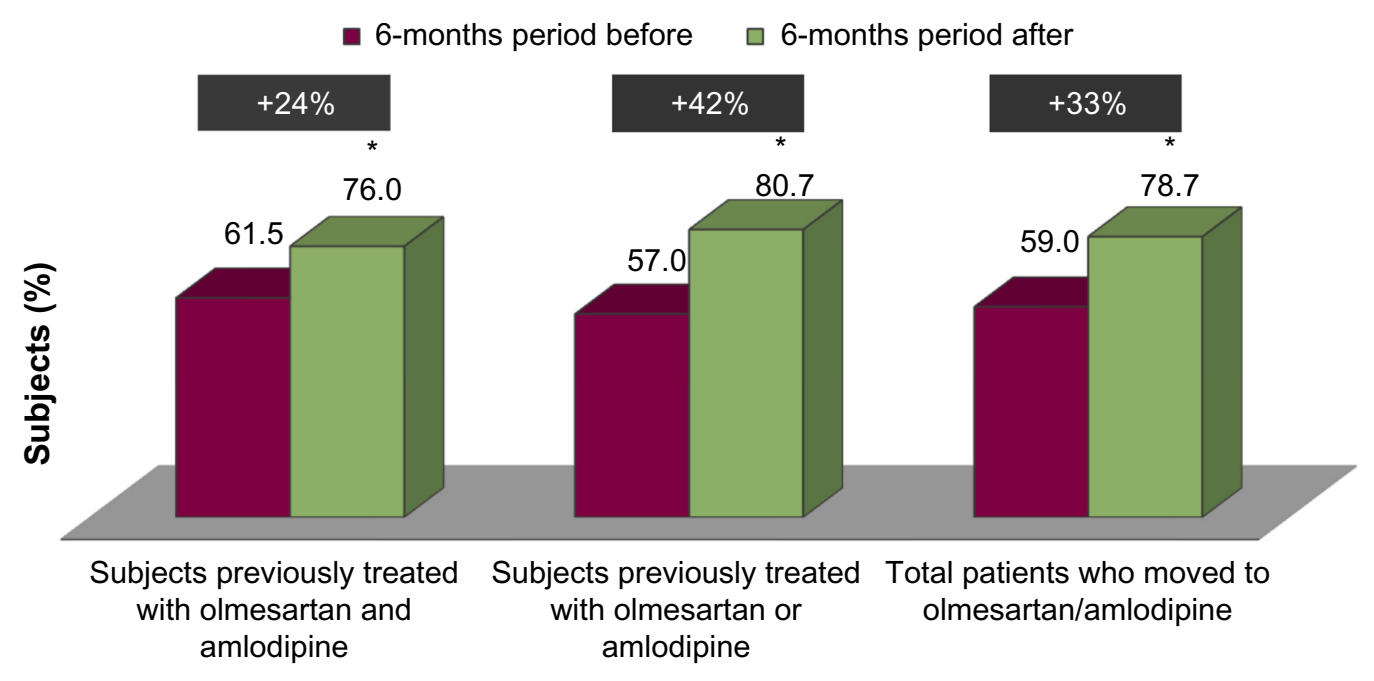

Figure 2 Adherence to treatment in subjects who moved to olmesartan/amlodipine.

Notes: Comparison between the 6-month period before and after the index date. Analysis of the 239 subjects who moved to olmesartan/amlodipine: 104 previously treated with olmesartan and amlodipine as a two-pill combination treatment, and I 35 previously treated with olmesartan or amlodipine as a single-pill treatment. $* P<0.00$ I postindex date period versus preindex date period. 


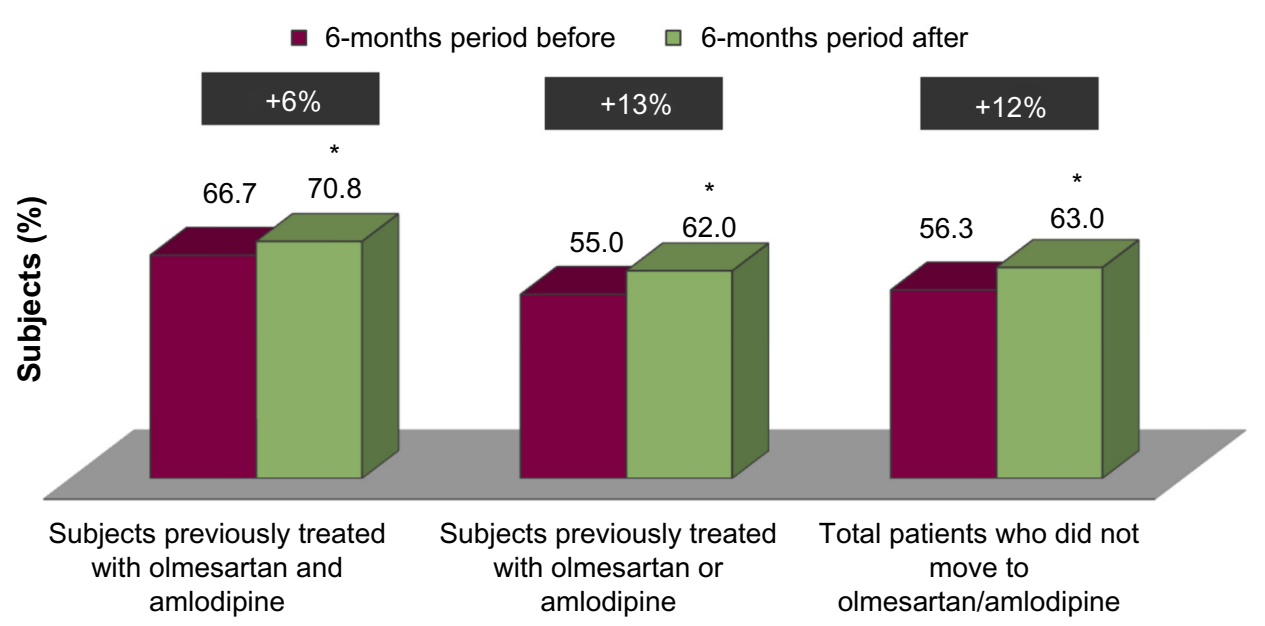

Figure 3 Adherence to treatment in subjects who did not move to olmesartan/amlodipine.

Notes: Comparison between the 6-month period before and after the index date. Analysis of the 20,769 subjects who did not move to olmesartan/amlodipine: 2,291 previously treated with olmesartan and amlodipine as a two-pill combination treatment, and 18,478 previously treated with olmesartan or amlodipine as a single-pill treatment. $* \mathrm{P}<0.00 \mathrm{I}$ postindex date period versus preindex date period.

advantages in terms of BP improvements and reductions in adverse effects. ${ }^{26,27}$ A large retrospective database study of an angiotensin II receptor blocker plus a calcium channel blocker in a two-drug, single-pill combination has also shown greater levels of adherence when compared with corresponding regimens consisting of a free-pill angiotensin II receptor blocker plus a calcium channel blocker. ${ }^{28}$ Moreover, Chang et $\mathrm{al}^{29}$ have shown that patients using a valsartan-based, singlepill combination were more adherent to pharmacological treatment, as well as more prone to achieve BP goals, than patients treated with an angiotensin II receptor blocker in free combination with other antihypertensive drugs.

The results of the present study performed in a clinical practice setting confirm that the rate of adherence on antihypertensive treatment is higher for hypertensive patients treated with a single-pill combination of olmesartan/amlodipine, as compared to patients treated with the two-pill combination or a single pill, or with other single or multipill ADTs. We suggest the possibility that the tolerability profile of the fixed combination of olmesartan/amlodipine might contribute to the patient's persistence on treatment. Unfortunately, the occurrence of drug-related adverse effects was not reported in pharmaceutical databases; however, some evidence might be obtained by the analysis of data collected from clinical trials comparing olmesartan/amlodipine with their respective monotherapies. These studies described an incidence of drug-related adverse events in the range of $5.3 \%-7.7 \%$ among patients receiving approved doses of olmesartan/amlodipine, compared with the incidence rates of $7.4 \%$ and $8.9 \%$ among patients receiving amlodipine or olmesartan monotherapy, respectively. ${ }^{30,31}$ Our findings suggest that the combination pill improves medication adherence. Fur- ther analyses are needed to confirm whether a higher proportion of patients who persist on treatment are associated with greater $\mathrm{BP}$ decreases in response to antihypertensive drugs.

The point of this study is that the pharmaceutical databases were constructed to serve a billing role for the reimbursement of services provided; thus, information on patients' BP levels was not available. However, a recent meta-analysis of 147 trials showed a BP-lowering benefit following the use of antihypertensive drugs, irrespective of what the patients' BP levels were, thus avoiding the need to measure BP routinely. ${ }^{32}$ This supports the hypothesis that the overall impact of the BP-lowering treatments in clinical practice may actually result from the treatments' absolute BP-lowering effect and their capacity to positively promote patients' persistence on treatment. From a public health perspective, studies based on administrative databases, like the present one, offer several advantages, including a prompt, easily updated, and representative picture of monitored cohorts with highly generalizable results. The ability for a health care system to be supported also depends on accurate and comprehensive data for good clinical management, administration, financial control, and general management. ${ }^{33}$ Thus, government institutions have stressed the importance of implementing patient-oriented clinical information systems, and of using the administrative databases in monitoring clinical practice. ${ }^{34}$

\section{Conclusion}

In conclusion, the results of the present study show that the rate of adherence to therapy can significantly differ among patients treated with several classes of antihypertensive drugs (even within the same pharmacological family), and among patients 
treated with the fixed combination of olmesartan/amlodipine. Additional studies are needed to assess whether these differences will be maintained in the following years, and whether the differences are associated with better health outcomes.

\section{Acknowledgments}

The development of this study was neither funded nor supported. The writing of this manuscript was supported with an unrestricted grant by Menarini, which played no role in the design of the study, analysis, or interpretation of the findings, nor in the preparation, review, and approval of the manuscript.

\section{Disclosure}

The authors report no conflicts of interest in this work.

\section{References}

1. Egan BM, Zhao Y, Axon RN. US trends in prevalence, awareness, treatment, and control of hypertension, 1988-2008. JAMA. 2010;303(20): 2043-2050.

2. Ezzati M, Oza S, Danaei G, Murray CJ. Trends and cardiovascular mortality effects of state-level blood pressure and uncontrolled hypertension in the United States. Circulation. 2008;117(7):905-914.

3. [No authors listed]. Prevalence of chronic diseases in older Italians: comparing self-reported and clinical diagnoses. The Italian Longitudinal Study on Aging Working Group. Int J Epidemiol. 1997;26(5):995-1002.

4. De Giusti M, Dito E, Pagliaro B, et al. A survey on blood pressure levels and hypertension control in a sample of the Italian general population. High Blood Press Cardiovasc Prev. 2012;19(3):129-135.

5. Krause T, Lovibond K, Caulfield M, McCormack T, Williams B; Guideline Development Group. Management of hypertension: summary of NICE guidance. BMJ. 2011;343:d4891.

6. Chobanian AV, Bakris GL, Black HR, et al; Joint National Committee on Prevention, Detection, Evaluation, and Treatment of High Blood Pressure. National Heart, Lung, and Blood Institute; National High Blood Pressure Education Program Coordinating Committee. Seventh report of the Joint National Committee on Prevention, Detection, Evaluation, and Treatment of High Blood Pressure. Hypertension. 2003;42(6):1206-1252.

7. Mancia G, De Backer G, Dominiczak A, et al; Management of Arterial Hypertension of the European Society of Hypertension; European Society of Cardiology. 2007 Guidelines for the management of arterial hypertension: The Task Force for the Management of Arterial Hypertension of the European Society of Hypertension (ESH) and of the European Society of Cardiology (ESC). J Hypertens. 2007;25(6): 1105-1187.

8. Cheung BM, Lau CP, Kumana CR. Combination therapy for hypertension. Hong Kong Med J. 2003;9(3):224-226.

9. Frank J. Managing hypertension using combination therapy. Am Fam Physician. 2008;77(9):1279-1286.

10. Di Bari M, Balzi D, Roberts AT, et al. Prognostic stratification of older persons based on simple administrative data: development and validation of the "Silver Code," to be used in emergency department triage. $J$ Gerontol A Biol Sci Med Sci. 2010;65(2):159-164.

11. Brocco S, Visentin C, Fedeli U, et al. Monitoring the occurrence of diabetes mellitus and its major complications: the combined use of different administrative databases. Cardiovasc Diabetol. 2007;6:5.

12. Ministero del lavoro, della Salute e delle Politiche Sociali. Rapporto annuale sulle attività di ricovero ospedaliero [Annual report on the activities of hospitalization]. 2009. Available from: http://www. salute.gov.it/imgs/C_17_pubblicazioni_1491_allegato.pdf. Accessed December 22, 2013. Italian.
13. Degli Esposti L, Degli Esposti E, Valpiani G, et al. A retrospective, population-based analysis of persistence with antihypertensive drug therapy in primary care practice in Italy. Clin Ther. 2002;24(8):1347-1357.

14. Catalan VS, LeLorier J. Predictors of long-term persistence on statins in a subsidized clinical population. Value Health. 2000;3(6): 417-426.

15. Ho PM, Rumsfeld JS, Masoudi FA, et al. Effect of medication nonadherence on hospitalization and mortality among patients with diabetes mellitus. Arch Intern Med. 2006;166:1836-1841.

16. Degli Esposti L, Valpiani G. Pharmacoeconomic burden of undertreating hypertension. Pharmacoeconomics. 2004;22(14):907-928.

17. Paramore LC, Halpern MT, Lapuerta P, et al. Impact of poorly controlled hypertension on healthcare resource utilization and cost. Am J Manag Care. 2001;7(4):389-398.

18. McCombs JS, Nichol MB, Newman CM, Sclar DA. The costs of interrupting antihypertensive drug therapy in a Medicaid population. Med Care. 1994;32(3):214-226.

19. Bloom BS. Continuation of initial antihypertensive medication after 1 year of therapy. Clin Ther. 1998;20(4):671-681.

20. Caro JJ, Salas M, Speckman JL, Raggio G, Jackson JD. Persistence with treatment for hypertension in actual practice. CMAJ. 1999;160(1): 31-37.

21. Degli Esposti L, Saragoni S, Benemei S, et al. Adherence to antihypertensive medications and health outcomes among newly treated hypertensive patients. Clinicoecon Outcomes Res. 2011;3:47-54.

22. Degli Esposti L, Saragoni S, Batacchi P, et al. Adherence to statin treatment and health outcomes in an Italian cohort of newly treated patients: results from an administrative database analysis. Clin Ther. 2012;34(1):190-199.

23. Virnig BA, McBean M. Administrative data for public health surveillance and planning. Ann Rev Public Health. 2001;22:213-230.

24. Black N. Why we need observational studies to evaluate the effectiveness of health care. BMJ. 1996;312(7040):1215-1218.

25. Ho PM, Bryson CL, Rumsfeld JS. Medication adherence: its importance in cardiovascular outcomes. Circulation. 2009;119(23):3028-3035.

26. Bangalore S, Kamalakkannan G, Parkar S, Messerli FH. Fixed-dose combinations improve medication compliance: a meta-analysis. Am J Med. 2007;120(8):713-719.

27. Gupta AK, Arshad S, Poulter NR. Compliance, safety, and effectiveness of fixed-dose combinations of antihypertensive agents: a meta-analysis. Hypertension. 2010;55(2):399-407.

28. Zeng F, Patel BV, Andrews L, Frech-Tamas F, Rudolph AE. Adherence and persistence of single-pill ARB/CCB combination therapy compared to multiple-pill ARB/CCB regimens. Curr Med Res Opin. 2010;26(12): 2877-2887.

29. Chang J, Yang W, Fellers T, et al. Chart review of patients on valsartanbased single-pill combinations vs ARB-based free combinations for BP goal achievement. Curr Med Res Opin. 2010;26(9):2203-2212.

30. Volpe M, Brommer P, Haag U, Miele C. Efficacy and tolerability of olmesartan medoxomil combined with amlodipine in patients with moderate to severe hypertension after amlodipine monotherapy: a randomized, double-blind, parallel-group, multicentre study. Clin Drug Investig. 2009;29(1):11-25.

31. Barrios V, Brommer P, Haag U, Calderón A, Escobar C. Olmesartan medoxomil plus amlodipine increases efficacy in patients with moderate-to-severe hypertension after monotherapy: a randomized, double-blind, parallel-group, multicentre study. Clin Drug Investig. 2009;29(7):427-439.

32. Law MR, Morris JK, Wald NJ. Use of blood pressure lowering drugs in the prevention of cardiovascular disease: meta-analysis of 147 randomised trials in the context of expectations from prospective epidemiological studies. BMJ. 2009;338:b1665.

33. Riley GF. Administrative and claims records as sources of health care cost data. Med Care. 2009;47:S51-S55.

34. Dick RS, Steen EB, editors. The Computer-Based Patient Record: An Essential Technology for Health Care. Washington, DC: National Academy Press; 1991. 


\section{Publish your work in this journal}

ClinicoEconomics \& Outcomes Research is an international, peerreviewed open-access journal focusing on Health Technology Assessment, Pharmacoeconomics and Outcomes Research in the areas of diagnosis, medical devices, and clinical, surgical and pharmacological intervention. The economic impact of health policy and health systems

organization also constitute important areas of coverage. The manuscript management system is completely online and includes a very quick and fair peer-review system, which is all easy to use. Visit http://www.dovepress.com/testimonials.php to read real quotes from published authors.

Submit your manuscript here: http://www.dovepress.com/clinicoeconomics-and-outcomes-research-journal 